\title{
Determination of Leaf Area of Some Vegetable Plants Grown under Greenhouse Condition by Non- Destructive Methods
}

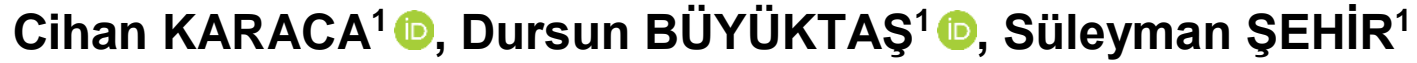

\author{
${ }^{1}$ Akdeniz University Faculty of Agriculture Department of Agricultural Structures and Irrigation, 07058 \\ Antalya / Turkey
}

\section{Article History}

Received 26 October 2020

Accepted 15 December 2020

First Online 21 December 2020

\section{Corresponding Author}

E-mail: cihankaraca@akdeniz.edu.tr

\author{
Keywords \\ Solanum lycopersicum L. \\ Solanum melongena $\mathrm{L}$. \\ Capsicum annuum L. \\ Cucumis sativus $\mathrm{L}$. \\ Regression
}

\begin{abstract}
The use of a mathematical model approach, which is a non-destructive method to determine the leaf area, has been used safely in recent years. The most important reason for this is that the application is easy and the application cost is very low. The most important disadvantage of this method is that the derived models need calibration according to different crop varieties. In the study, firstly, the width (W) and length (L) measurements of each individual leaf taken from the crops were correlated with the actual area of the leaf and crop-specific models were developed. The actual area (LA) of each leaf used in the sampling was determined by the ImageJ software. In the study, 7 different models were derived for each crop species (1, $L A=a+b L^{2}+c L^{2} W^{2}+d W^{2}+e L W ; 2, L A=a+b L^{2}+c W^{2}+d L W ; 3, L A=a+b L^{2}+c W^{2} ; 4$, $\left.L A=a L^{2}+b W^{2} ; 5, L A=a L^{b}+c W^{d}+e ; 6, L A=a+b L W ; 7, L A=a L W\right)$. The coefficients in the models were determined separately for each crop species. In order to evaluate the performance of the models, some performance criteria such as determination coefficient $\left(R^{2}\right)$ and root mean square error (RMSE), relative error (RE), mean bias error (MBE) and Willmott index (d) were used. In this study, leaf areas were estimated with high accuracy $\left(R^{2}=0.96\right.$ for tomato; $R^{2}=0.99$ for pepper, eggplant and cucumber) with these models without using expensive measuring devices.
\end{abstract}

\section{Introduction}

The leaves of each crop varieties have a characteristic size. Moreover, there is a direct relationship between the width, length and area of the leaf (Al Mamun Hossain et al., 2017; Hinnah et al., 2014; Ray and Singh, 1989). For this reason, a large number of equations developed in order to estimate the leaf area by using leaf width and length values. The characteristic leaf dimension can show variability even in different varieties of the same species of plant. Therefore, as can be seen in Table 1 , a large number of models were developed by researchers. Table 1 shows the different models used to estimate the leaf area of different crop species and varieties in different environments (Karaca, 2020).
There are two destructive and non-destructive categories which include counting squares on millimeter graph paper, hand-planimetry, the gravimetric method, dot counting, photoelectric planimetry, air-flow, linear measurements of leaves, leaf weighing, detached leaf counting, and the rating in determining leaf area (Pandey and Singh, 2011). In the destructive method, the leaves are separated from the plant body and the area is determined with the help of various scanning planimeters. However, destructive methods require more intensive labor and higher costs. In recent years, the portable types of these instruments were developed and the leaf area was measured without being destructive. However, in this method, leaf size, shape and texture are limiting and do not suitable for every plant leaf (Rouphael et al., 2010). 
Table 1. Models used to predict leaf areas of different crop species in different growing environments

\begin{tabular}{|c|c|c|c|}
\hline Environments & Plant & Equation & Source \\
\hline Open Field & Eggplant & $L A=0.66 L W-0.00008 \mathrm{LW}^{2}$ & (Rivera et al., 2007) \\
\hline Open Field & Eggplant & $L A=0.6537 L W+3.14$ & (Ogoke et al., 2015) \\
\hline Greenhouse & Eggplant & $L A=0.4395 L W^{1.0055}$ & (Hinnah et al., 2014) \\
\hline Greenhouse & Cucumber & $L A=0.859 L W+2.7$ & (Blanco and Folegatti, 2003) \\
\hline Greenhouse & Cucumber & $L A=10.3602+0.7001 W^{2}$ & (Bozkurt and Keskin, 2018) \\
\hline Greenhouse & Cucumber & $L A=-28.5522+0.8301 L^{2}$ & (Bozkurt and Keskin, 2018) \\
\hline Greenhouse & Cucumber & $L A-3.6852+0.5202 W^{2}+0.2252 L^{2}$ & (Bozkurt and Keskin, 2018) \\
\hline Open Field & Cucumber & $L A=210.61+13.358 W+0.5356 L W$ & (Cho et al., 2007) \\
\hline Greenhouse & Tomato & $L A=0.347 L W-10.7$ & (Blanco and Folegatti, 2003) \\
\hline Greenhouse & Tomato & $L A=0.2695 L^{0.4759} \mathrm{~W}^{1.4184}$ & (Schwarz and Kläring, 2001) \\
\hline Greenhouse & Tomato & $L A=0.2633 L \mathrm{~W}^{1.1175}$ & (Dumas, 1990) \\
\hline Open Field & Pepper & $L A=0.604 L W$ & (Ray and Singh, 1989) \\
\hline Open Field & Bell pepper & $L A=0.57 L W$ & (Padrón et al., 2016) \\
\hline Greenhouse & Green pepper & $L A=-8.28+1.89 L+2.5 W+0.0028 L W$ & (Cemek et al., 2011) \\
\hline Greenhouse & Chili Pepper & $L A=0.498 L W+0.054$ & (Aminifard et al., 2017) \\
\hline
\end{tabular}

Non-destructive methods are widely used because they do not require the leaves to be plucked, therefore do not adversely affect plant growth and allow measurements to be repeated throughout the growing period. Simple and accurate mathematical models that reveal the relationship between leaf area and leaf dimensions (width and length) have been developed by many researchers for many plant species as they eliminate the dependence on expensive measuring devices and, save time (Carmassi et al., 2007).

In this study, empirical models were derived and tested to estimate the leaf area depending on the leaf width and length for four different crop species (tomato, eggplant, pepper and cucumber) commonly grown under greenhouse conditions in Antalya. For this purpose, seven different models were developed for each crop Different statistical performance criteria were used to determine the performance of these models.

\section{Material and Methods}

This study was carried out under the conditions of a lysimeter in a plastic greenhouse in the experimental area of the Faculty of Agriculture, Akdeniz University. The first and second seasons of the experiment were conducted from 14.09.2018 to 21.02.2019. Anit $\mathrm{F} 1$ in tomato, Ayda $\mathrm{F1}$ in cucumber, Corsica F1 in eggplant and Buket F1 in pepper varieties, which is suitable for both autumn and spring cultivation in Antalya Region, were used as crop material.

One hundred thirty-five leaves were used for each crop species to derive leaf area prediction models. Leaf length $(\mathrm{L})$ was measured with a ruler, disregarding the petiole (except tomato). Leaf length in tomato was measured as the distance from the base of the petiole to the distal tip. Leaf width (W) was determined by measuring the longest width of the leaves perpendicularly to the midrib. The actual leaf area was obtained with Image $\mathbb{R}$ software after scanning the measured leaves
(Ferreira and Rasband, 2012) (Figure 1). The relationship between leaf dimensions and leaf area (LA) was determined by seven models for each crop.

Model 1: $L A=a+b L^{2}+C^{2} / W^{2}+d W^{2}+e L W$

Model 2: $L A=a+b L^{2}+c W^{2}+d L W$

Model 3: $L A=a+b L^{2}+c W^{2}$

Model 4: $\mathrm{LA}=\mathrm{aL}^{2}+\mathrm{bW}^{2}$

Model 5: $L A=a L b+c W d+e$

Model 6: $L A=a+b L W$

Model 7: $L A=a L W$

The coefficients (a, b, c, d and e) in the models were derived separately for each plant species.

In order to determine the most accurate model, some statistical performance criteria including coefficient of determination $\left(\mathrm{R}^{2}\right)$ (Equation 1), root mean square error (RMSE) (Equation 2), relative error (RE) (Equation 3), mean bias error (MBE) (Equation 4), the Willmott index of agreement (d) (Equation 5) were used.

$$
\begin{aligned}
& R^{2}=\frac{\left[\sum_{i=1}^{n}\left(X_{i}-\ddot{X}\right)\left(Y_{i}-\hat{Y}\right)\right]^{2}}{\sum_{i=1}^{n}\left(X_{i}-\ddot{X}\right)^{2} \sum_{i=1}^{n}\left(Y_{i}-\hat{Y}\right)^{2}} \\
& R M S E=\sqrt{\frac{\sum_{i=1}^{n}\left(X_{i}-Y_{i}\right)^{2}}{n}} \\
& R E=\frac{R M S E}{\hat{Y}} \\
& M B E=\frac{\sum_{i=1}^{n}\left(X_{i}-Y_{i}\right)}{n} \\
& d=1-\frac{\sum_{i=1}^{n}\left(X_{i}-Y_{i}\right)^{2}}{\sum_{i=n}^{n}\left(\left(X_{i}-\hat{Y}_{i}\right)+\left(Y_{i}-\hat{Y}_{i}\right)\right)^{2}}
\end{aligned}
$$

Where $\mathrm{n}$ is number of observations, $\mathrm{Xi}$ is the indirectly estimated $L A, Y i$ is directly measured $L A$ and $\ddot{X}$ is mean value of estimated $L A$ and $\hat{Y}$ is mean value of measured LA. RMSE, RE and MBE are 0 , while $R^{2}$ and $d$ are 1 indicate that the prediction model is perfect. In the study, "data analysis" and "solver" add-ons of Microsoft Excel program were used to calculate the coefficients of the models. 


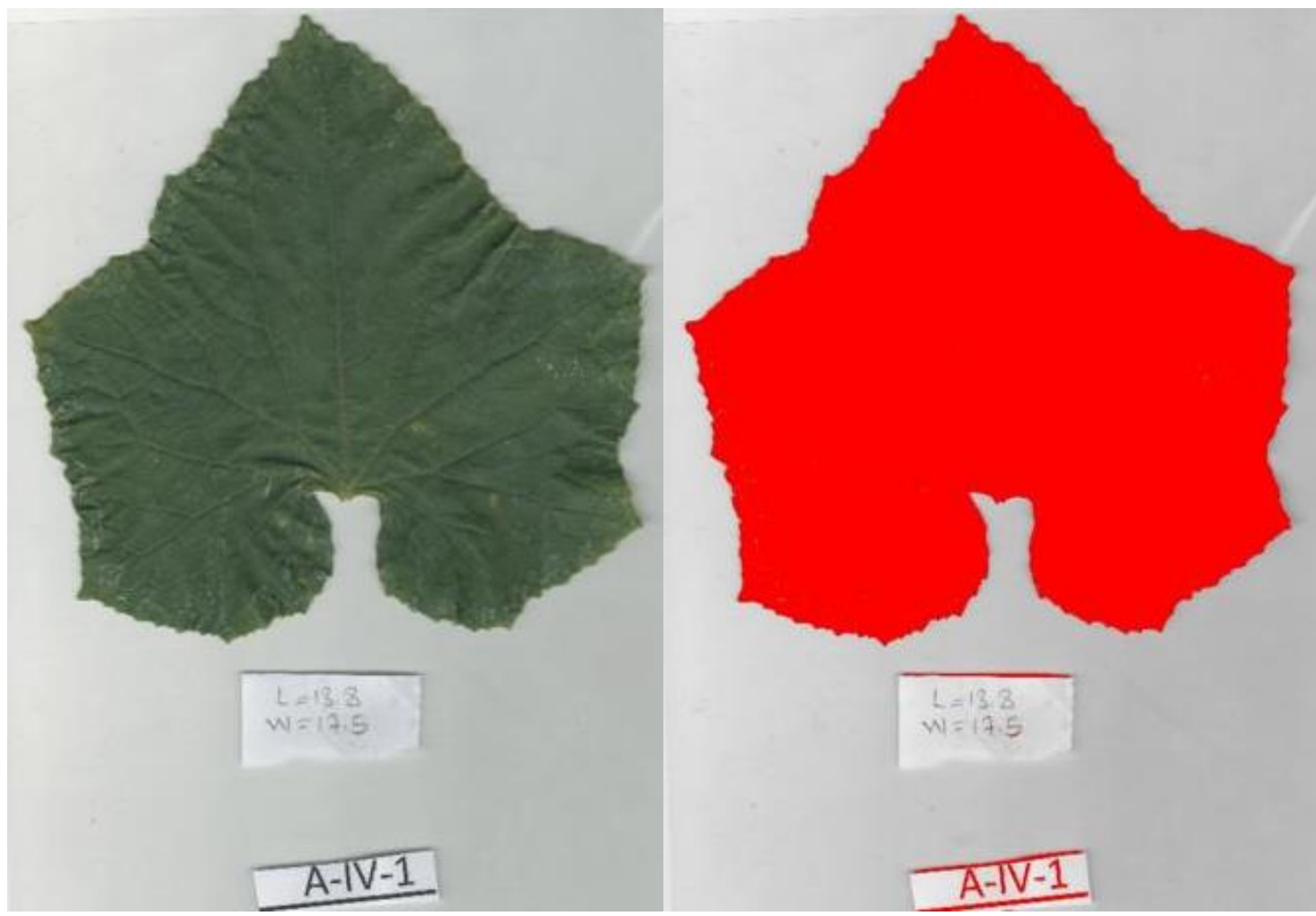

Figure 1. Determination of actual leaf area with ImageJ software

Table 2. Average data comparison of length, width and area of leaves in four different crop obtained by ImageJ® software

\begin{tabular}{llrrrr}
\hline \multirow{2}{*}{ Plant } & \multicolumn{1}{c}{ Dimension } & Mean & SD & Min & Max \\
\hline \multirow{3}{*}{ Tomato } & Length $(\mathrm{cm})$ & 23.6 & 7.4 & 11.9 & 39.0 \\
& Width $(\mathrm{cm})$ & 27.5 & 8.0 & 11.2 & 42.6 \\
& Area $\left(\mathrm{cm}^{2}\right)$ & 315.6 & 187.2 & 44.8 & 885.2 \\
\hline \multirow{3}{*}{ Eggplant } & Length $(\mathrm{cm})$ & 17.7 & 5.7 & 8.9 & 28.5 \\
& Width $(\mathrm{cm})$ & 11.0 & 4.1 & 5.2 & 19.4 \\
& Area $\left(\mathrm{cm}^{2}\right)$ & 138.5 & 83.2 & 35.7 & 305.2 \\
\hline \multirow{3}{*}{ Pepper } & Length $(\mathrm{cm})$ & 7.8 & 2.5 & 4.1 & 11.8 \\
& Width $(\mathrm{cm})$ & 3.9 & 1.2 & 1.9 & 6.3 \\
& Area $\left(\mathrm{cm}^{2}\right)$ & 20.4 & 3.8 & 46.3 \\
\hline \multirow{2}{*}{ Cucumber } & Length $(\mathrm{cm})$ & 13.1 & 4.9 & 9.6 & 18.0 \\
& Width $\left(\mathrm{cm}^{2}\right.$ & 16.7 & 91.4 & 62.6 & 23.6 \\
& Area $\left(\mathrm{cm}^{2}\right)$ & & & 359.6 \\
\hline
\end{tabular}

\section{Results and Discussion}

The mean, maximum (Max), minimum (Min) and standard deviation (SD) for area of leaves, length $(\mathrm{L})$ and width $(\mathrm{W})$, were given in Table 2.

In many studies (Aminifard et al., 2017; Hinnah et al., 2014; Ogoke et al., 2015; Padrón et al., 2016), leaf sizes were used to determine the leaf area. Therefore, in this study, LA was related to $L, W$ and $\mathrm{L} \times \mathrm{W}$ in variations. The coefficients of the models used to determine the leaf areas of four different crops were given in Table 3 and the performance criteria of these models in Table 4.

Although the $R^{2}$ value is considered as a measure of accuracy in determining the performance of the estimation equation, it is not sufficient to be certain. The most important thing is to obtain a low error (Cemek et al., 2011). The most accurate result is obtained when RMSE, RE and
$M B E$ are equal to 0 and $d$ and $R^{2}$ equal to 1 (Karaca et al., 2018). For this purpose RMSE, RE, MBE, and $d$ values in Table 4 were also examined.

$R^{2}$ values of all models except for Model 5 in the tomato were 0.96 . The lowest RMSE value (37.67) in tomato is determined in Model 1. RMSE values of Models 2, 3 and 6 are close to model 1. However, the RMSE performances of Models 4, 5 and 7 are lower than other models. When the MBE value was investigated, it was seen that Model 6 gave the best result. Models 4, 5 and 7 performed lower than other models. When $d$ performance criterion was examined, although the results were very close to each other, Model 4 and 7 had lower performance compared to other models (Table 4). Blanco and Folegatti (2003) reported that the predictive performance (R2) of LA values of tomato plants with three different non-destructive models was between 0.95 and 0.98 . On the other hand, Schwarz and 
Table 3. The coefficients of the models used to determine the leaf area of four different crops

\begin{tabular}{|c|c|c|c|c|c|c|c|}
\hline \multirow{2}{*}{ No } & \multirow{2}{*}{ Model } & \multirow{2}{*}{ Crop } & \multicolumn{5}{|c|}{ Equation Coefficient } \\
\hline & & & $\mathrm{a}$ & $\mathrm{b}$ & $\mathrm{c}$ & $\mathrm{d}$ & e \\
\hline \multirow{4}{*}{1} & \multirow{4}{*}{$L A=a+b L^{2}+c L^{2} / W^{2}+d W^{2}+e L W^{*}$} & Tomato & -42.46 & -0.48 & 6.48 & -0.41 & 1.31 \\
\hline & & Eggplant & 31.53 & 1.26 & -9.51 & 2.75 & -3.15 \\
\hline & & Pepper & 4.72 & -0.37 & -0.91 & -1.69 & 2.19 \\
\hline & & Cucumber & -38.56 & -2.35 & 50.75 & -1.18 & 4.20 \\
\hline \multirow{4}{*}{2} & \multirow{4}{*}{$L A=a+b L^{2}+c W^{2}+d L W$} & Tomato & -35.98 & -0.38 & -0.33 & 1.13 & - \\
\hline & & Eggplant & 3.00 & 0.86 & 2.04 & -2.05 & - \\
\hline & & Pepper & 0.97 & -0.47 & -1.76 & 2.42 & . \\
\hline & & Cucumber & -3.81 & -0.52 & -0.22 & 1.53 & - \\
\hline \multirow{4}{*}{3} & \multirow{4}{*}{$L A=a+b L^{2}+c W^{2}$} & Tomato & -46.04 & 0.15 & 0.28 & - & - \\
\hline & & Eggplant & 4.22 & 0.19 & 0.50 & - & - \\
\hline & & Pepper & 0.98 & 0.15 & 0.57 & - & - \\
\hline & & Cucumber & -3.96 & 0.43 & 0.39 & - & - \\
\hline \multirow{4}{*}{4} & \multirow{4}{*}{$L A=a L^{2}+b W^{2}$} & Tomato & 0.11 & 0.28 & - & - & - \\
\hline & & Eggplant & 0.20 & 0.50 & - & - & - \\
\hline & & Pepper & 0.16 & 0.59 & - & - & - \\
\hline & & Cucumber & 0.38 & 0.41 & - & - & - \\
\hline \multirow{4}{*}{5} & \multirow{4}{*}{$L A=a L^{b}+c W^{d}+e$} & Tomato & -19.17 & -317.04 & 0.10 & 2.39 & 5.00 \\
\hline & & Eggplant & -19.17 & -317.04 & 6.06 & 1.36 & -25.41 \\
\hline & & Pepper & -19.17 & -317.04 & 2.87 & 1.52 & -3.19 \\
\hline & & Cucumber & -19.17 & -317.04 & 0.43 & 2.10 & 15.17 \\
\hline \multirow{4}{*}{6} & \multirow{4}{*}{$L A=a+b L W$} & Tomato & -45.08 & 0.42 & - & - & - \\
\hline & & Eggplant & 3.99 & 0.62 & - & - & - \\
\hline & & Pepper & 0.96 & 0.59 & - & - & - \\
\hline & & Cucumber & -6.29 & 0.85 & - & - & - \\
\hline \multirow{4}{*}{7} & \multirow{4}{*}{$L A=a L W$} & Tomato & 0.38 & - & - & - & - \\
\hline & & Eggplant & 0.64 & - & - & - & - \\
\hline & & Pepper & 0.61 & - & - & - & - \\
\hline & & Cucumber & 0.83 & - & - & - & - \\
\hline
\end{tabular}

a, b, c, d and e: Equation coefficient; LA: Mean leaf area $\left(\mathrm{cm}^{2}\right)$; L: Leaf lenght $\left(\mathrm{cm}^{2}\right)$; W: Leaf width $\left(\mathrm{cm}^{2}\right)$

Kläring (2001) used two different methods to estimate the LA values of tomato plants: leaf length measurements from the stem and the rachis where the first pinnate starts. In that study where ten different non-destructive models were tested, the researchers stated that the $R^{2}$ prediction performance was between 0.73 and 0.91 and they recommended that the leaf length should be measured from the stem. Similarly, in our study, leaf length was measured from the stem. In addition, the performances obtained from the models had a high performance as in the literature.

$R^{2}$ values in the eggplant ranged from 0.99 to 0.94 . Model 5 was the lowest performing model compared to the others with 0.94 , while the other models showed very close results (Table 4). While the lowest RMSE value was in Model 1 (8.88), the highest RMSE value was in Model 5 (19.34). Similar to $R^{2}$, the performances of other models in RMSE value showed results close to Model 1 . When the MBE criterion was examined, the highest performance belonged to Model 6 with -0.000002 while models 1,4 and 7 had relatively worse performance. Rivera et al. (2007) analyzed six different models to estimate the LA value of the eggplant and determined that the $\mathrm{R}^{2}$ values of these models were between 0.73 and 0.97 and the MSE values were between 725 and $88 \mathrm{~cm}^{2}$. Hinnah et al. (2014) estimated the LA values of the eggplant with twelve different models and determined that the $\mathrm{R}^{2}$ values of the models used were between 0.92 and 0.98 , the RMSE values were between 33.2 and
$77.8 \mathrm{~cm}^{2}$, and the MAE values were between 23.36 and $68.59 \mathrm{~cm}^{2}$. Therefore, in our study, it was determined that the performances of the models tried to estimate the LA value of the eggplant were similar to previous studies.

In the pepper plant, $\mathrm{R}^{2}$ values of all models except Model 5 were determined as 0.99. Model 5, with a value of 0.94 , was the model with the lowest performance compared to other models. When the RMSE performances of the models were evaluated, again Model 5 showed lower performance than other models. RMSE values of all models were close to each other. When the MBE values were examined, the highest performance was obtained in Model 6 (-0.000004), similar to other crops. $d$ performance criteria were 1.00 for all models. Cemek et al. (2011) derived prediction models to determine LA of pepper plant under different salt and water stress. Researchers have stated that the models they developed to estimate the leaf area of green peppers grown under different stress conditions and levels could be used reliably. Aminifard et al. (2017) added leaf fresh and dry weight parameters to some of these models, unlike other studies in the literature, in order to estimate LA value. They reported that new parameters based on leaf weights did not give good results in predicting LA value. In our study, it was determined that the models used to predict LA values of pepper had high performance similar to the literature.

Since $\mathrm{R}^{2}$ performance values of all models in the cucumber plant varied between 0.98 and 0.99 , there 
Table 4. The performance criteria of the models used to determine the leaf area of four different crops

\begin{tabular}{|c|c|c|c|c|c|c|}
\hline \multirow{2}{*}{ Models } & \multirow{2}{*}{ Crop } & \multicolumn{5}{|c|}{ Performance criteria } \\
\hline & & $\mathrm{R}^{2}$ & RMSE & $\mathrm{RE}$ & MBE & $d$ \\
\hline \multirow{4}{*}{1} & Tomato & 0.96 & 37.67 & 0.1194 & 0.0041 & 0.99 \\
\hline & Eggplant & 0.99 & 8.88 & 0.0643 & 0.0048 & 1.00 \\
\hline & Pepper & 0.99 & 1.07 & 0.0525 & 0.0000 & 1.00 \\
\hline & Cucumber & 0.99 & 10.92 & 0.0570 & -0.0027 & 1.00 \\
\hline \multirow{4}{*}{2} & Tomato & 0.96 & 37.69 & 0.1194 & 0.0034 & 0.99 \\
\hline & Eggplant & 0.99 & 9.53 & 0.0690 & 0.00002 & 1.00 \\
\hline & Pepper & 0.99 & 1.13 & 0.0555 & 0.00001 & 1.00 \\
\hline & Cucumber & 0.99 & 11.09 & 0.05791 & 0.00003 & 1.00 \\
\hline \multirow{4}{*}{3} & Tomato & 0.96 & 38.61 & 0.1223 & 0.00006 & 0.99 \\
\hline & Eggplant & 0.98 & 10.47 & 0.0758 & 0.00000 & 1.00 \\
\hline & Pepper & 0.99 & 1.28 & 0.0626 & 0.00000 & 1.00 \\
\hline & Cucumber & 0.99 & 11.11 & 0.0580 & 0.00001 & 1.00 \\
\hline \multirow{4}{*}{4} & Tomato & 0.96 & 43.53 & 0.1379 & -8.7819 & 0.98 \\
\hline & Eggplant & 0.98 & 10.67 & 0.0773 & 1.0774 & 1.00 \\
\hline & Pepper & 0.99 & 1.37 & 0.0669 & 0.2397 & 1.00 \\
\hline & Cucumber & 0.99 & 11.21 & 0.0586 & -0.5644 & 1.00 \\
\hline \multirow{4}{*}{5} & Tomato & 0.95 & 41.83 & 0.1325 & 2.6158 & 0.99 \\
\hline & Eggplant & 0.94 & 19.34 & 0.1401 & 0.0015 & 0.99 \\
\hline & Pepper & 0.94 & 2.68 & 0.1309 & 0.0000 & 0.99 \\
\hline & Cucumber & 0.98 & 13.53 & 0.0707 & 0.0149 & 0.99 \\
\hline \multirow{4}{*}{6} & Tomato & 0.96 & 38.82 & 0.1230 & 0.0001 & 0.99 \\
\hline & Eggplant & 0.98 & 11.17 & 0.0810 & 0.0000 & 1.00 \\
\hline & Pepper & 0.99 & 1.22 & 0.0597 & 0.0000 & 1.00 \\
\hline & Cucumber & 0.99 & 11.24 & 0.0587 & 0.0000 & 1.00 \\
\hline \multirow{4}{*}{7} & Tomato & 0.96 & 43.71 & 0.1385 & -8.9499 & 0.98 \\
\hline & Eggplant & 0.98 & 11.36 & 0.0823 & 1.0953 & 1.00 \\
\hline & Pepper & 0.99 & 1.31 & 0.0641 & 0.2364 & 1.00 \\
\hline & Cucumber & 0.99 & 11.57 & 0.0604 & -1.192 & 1.00 \\
\hline
\end{tabular}

$\mathrm{R}^{2}$ : Determination coefficient; RMSE: Root mean square error; RE: Relative error; MBE: Mean bias error, $\mathrm{d}$ : Willmott index of agreement.

is no significant difference between the models. When the RMSE values were examined, the best performance was in Model 1 (10.92). The performances of all models except Model 5 (13.53) were found close to Model 1 . Since the d values of the models vary between 0.99 and 1.00 , there was no difference between the models according to this performance criterion. Blanco and Folegatti (2003) derived different LA prediction models in different salinity and grafting conditions of cucumber. Bozkurt and Keskin (2018) found a high and nonlinear relationship between leaf area and leaf length and width of cucumber grown in greenhouse conditions. Researchers also derived special models for different deficit irrigation applications $\left(I_{120}, I_{100}, I_{80}, I_{60}, I_{40}\right.$, and $\left.I_{20}\right)$ and reported that all estimation models provide highly accurate predictions. Cho et al. (2007), differently, models were developed using leaf length, leaf width, SPAD value and different combinations of these variables to predict cucumber leaf area. But, the researchers determined that when the SPAD value was used, the performance of the prediction models decreased.

When the general performances of the models developed for the crops grown in the study were examined, it was determined that all models were acceptable. On the other hand, it was determined that model number 5 had the lowest $R^{2}$ and $d$ value and the highest RMSE, RE and MBE values in all varieties. For this reason, the Model 5 had the lowest performance among all models. Models 1 and 6 performed the highest performance compared to other models. In addition, the models and coefficients given in Tables 3 and 4 can be used safely for tomato, eggplant, pepper, and eggplant plants grown under greenhouse conditions.

\section{Conclusion}

In this experiment, firstly, seven different models were derived in order to determine the leaf area with a non-destructive method of four economically important horticulture greenhouse crops. Then, the performances of the derived models were examined. Performance analysis proved the accuracy of the models, and Model 1 $\left(L A=a+b L^{2}+\mathrm{CL}^{2} / \mathrm{W}^{2}+d W^{2}+\mathrm{eLW}\right)$ and Model 6 $(L A=a+b L W)$ gave the best performance. However, since it is easier to use, model 6 was suggested to use for estimation of the LA value of tomatoes, eggplants, peppers, and cucumber grown under greenhouse conditions.

\section{Acknowledgements}

This study was supported by Akdeniz University Research Funds, Grant No: FDK-2018-2966. Plant materials in this research was obtained from TOVAG: 1170071 numbered project -Scientific and the Technological Research Council of Turkey (TUBITAK). 


\section{References}

Al Mamun Hossain, S.A., Wang, L., Chen, T., \& Li, Z. (2017). Leaf area index assessment for tomato and cucumber growing period under different water treatments. Plant, Soil and Environment, 63:461-467.

Aminifard, M.H., Khayyat, M., \& Bayat, H. (2017). Individual Leaf area modelling of chili pepper (Capsicum frutescens) Using leaf dimensions and weight. Agricultural Communications, 5:1-6.

Blanco, F.F., \& Folegatti, M.V. (2003). A new method for estimating the leaf area index of cucumber and tomato plants. Horticultura Brasileira, 21:666-669.

Bozkurt, S., \& Keskin, M. (2018). Effect of deficit irrigation on the estimation of cucumber leaf area under greenhouse conditions. International Journal of Agriculture \& Biology, 20:877-882.

Carmassi, G., Incrocci, L., Incrocci, G., \& Pardossi, A. (2007). Non-destructive estimation of leaf area in tomato (Solanum lycopersicum L.) and gerbera (Gerbera jamesonii H. Bolus). Agricoltura Mediterranea, 137:172-176.

Cemek, B., Unlukara, A., \& Kurunc, A. (2011). Nondestructive leaf-area estimation and validation for green pepper (Capsicum annuum L.) grown under different stress conditions. Photosynthetica, 49:98106.

Cho, Y.Y., Oh, S., Oh, M.M., \& Son, J.E. (2007). Estimation of individual leaf area, fresh weight, and dry weight of hydroponically grown cucumbers (Cucumis sativus L.) using leaf length, width, and SPAD value. Scientia Horticulturae, 111:330-334.

Dumas, Y. (1990). Interrelation of linear measurements and total leaf area or dry matter production in young tomato plants. Advances in Horticultural Science, $4: 172-176$

Ferreira, T., \& Rasband, W. (2012). ImageJ User Guide User Guide ImageJ. Image J User Guide, IJ 1.46r, 185.
Hinnah, F.D., Heldwein, A.B., Loose, L.H., Lucas, D.D.P., Bortoluzzi, M.P., \& Maldaner, I.C. (2014). Estimation of eggplant leaf area from leaf dimensions. Bragantia, 73:213-218.

Karaca, C. (2020). Evapotranspiration of crops widely grown in greenhouses using the energy balance method. PhD Thesis, Akdeniz Ünivetrsity, Antalya, (In Turkish).

Ogoke, I.J., Ike, G.A., Echereobia, C.O., \& Ngwuta, A.A. (2015). Non-destructive leaf area determination in African eggplant. Agrosearch, 15:13-20.

Padrón, R.A.R., Lopes, S.J., Swarowsky, A., Cerquera, R.R., Nogueira, C.U., \& Maffei, M. (2016). Nondestructive models to estimate leaf area on bell pepper crop. Ciência Rural, 46:1938-1944.

Pandey, S.K., \& Singh, H. (2011). A simple, cost-effective method for leaf area estimation. Journal of Botany, 2011:1-6.

Ray, R.C., \& Singh, R.P. (1989). Leaf area estimation in capsicum (Capsicum annuum L.). Scientia Horticulturae, 39:181-188.

Rivera, C.M., Rouphael, Y., Cardarelli, M., \& Colla, G. (2007). A simple and accurate equation for estimating individual leaf area of eggplant from linear measurements. European Journal of Horticultural Science, 72:228-230.

Rouphael, Y., Mouneimne, A.H., Ismail, A., Mendoza-De Gyves, E., Rivera, C.M., \& Colla, G. (2010). Modeling individual leaf area of rose (Rosa hybrida L.) based on leaf length and width measurement. Photosynthetica, 48:9-15.

Schwarz, D., \& Kläring, H.P. (2001). Allometry to estimate leaf area of tomato. Journal of Plant Nutrition, 24:1291-1309. 